\title{
Scalar implicature in Chitonga-speaking children
}

Jodi Reich, Kelly Nedwick, Teodora Niculae-Caxi, Yang Liu, \& Elena L. Grigorenko*

\begin{abstract}
Research on the acquisition of scalar implicature (SI) has provided evidence that young children interpret SI differently from adults. However, results have varied, and there is now mounting evidence that around six years of age, children are able to derive the pragmatic inferences associated with SI (Foppolo, Guasti, and Chierchia, 2012). Variability in results across studies could be due to factors such as data collection methods and language-specific differences. In order to add to the growing body of literature in a meaningful way, this research investigated the interpretation of sentences that include SI by Chitonga-speaking children (7-15 years old) in rural Southern Province, Zambia, who were notably beyond the key age of six. The results of this study provide valuable insight into the interpretation of SI in a Bantu language and suggest that the acquisition of pragmatic felicity with words on a scale follows the order of acquisition identified in previous research, but may emerge at a later age in this linguistic context.
\end{abstract}

Keywords: scalar implicature; pragmatics; acquisition; Bantu; Chitonga

1. Introduction. Competent speakers are expected to communicate cooperatively, and, with this in mind, sentences with words on a scale are expected to be used in the most informative way possible. Scalar implicature (SI) is an inference derived from the use of a word on a scale (e.g., Grice, 1957). Examples include words such as some, and all. Some and all are on the scale some <many <most<all (Horn, 1972). Consider the sentences in (1), (2), and (3).

(1) The child ate some of the cookies.

(2) Not all of the cookies were eaten by the child.

(3) All of the cookies were eaten by the child.

In uttering the sentence in (1), it is technically possible for either the situation described in (2) or (3) to be true. Importantly, when all the cookies are eaten, it is true that some of the cookies, a subset of the total set of cookies, were eaten. However, based on Grice's Maxims, especially the Maxim of Quantity, adults will expect the situation in (2) when hearing the sentence in (1), and

\footnotetext{
*This research was supported by the NIH (TW008274, PI: Grigorenko). Grantees are encouraged to express their professional judgment. This article does not necessarily represent the policies or positions of the NIH. We would like to thank the children and communities that participated in this study as well as Ackim Mungo for his help in the preparation of this manuscript. Authors: Jodi Reich (jodi.reich@ @emple.edu), Teodora Niculae-Caxi, \& Yang Liu, Temple University; Kelly Nedwick, Sacred Heart University, and Elena L. Grigorenko, University of Houston.
} 
will rule out the situation described by (3). ${ }^{1}$ Cardinal numbers (e.g., 1, 2, 3) have also been categorized as scalar, but could also be analyzed as "generalized quantifiers over degrees" (Kennedy, 2013: 29). Both traditional scalar words and cardinal numbers are included in this study as resulting in SI.

Previous research has found evidence that young children interpret sentences with SI differently from adults. While adults interpret some as some, but not all, children at earlier ages interpret some as some and possibly all. Initial differences between the interpretations of children and adults with regard to SI have been attributed to processing limitations (e.g., Noveck, 2001). Research has attempted to identify the age at which children acquire adult-like interpretations; however, this research has led to inconsistent results. Although results have varied, there is evidence that typically developing children can master SI as young as six (e.g., Chierchia, Crain, Guasti, Gualmini, \& Meroni, 2001; Huang \& Snedeker, 2009; Foppolo, Guasti, \& Chierchia, 2012).

Multiple factors and their interactions could be impacting results and giving rise to the observed variability. Foppolo and colleagues (2012) propose the following possibilities: (1) the development of cognitive abilities (Shallice, 1982; Gopnik \& Rosati, 2001), (2) lexical maturation (Barner \& Bachrach, 2010), and (3) methodological differences across studies (Foppolo et al., 2012). An additional possibility is cross-linguistic variability. A number of different languages have been included in previous research, which adds to the breadth of our knowledge on the acquisition of SI, but also could explain the observed variability in results.

2. Current Study. This study extends research on SI acquisition to a language that has yet to be included in any study of SI acquisition - Chitonga. Chitonga is a Bantu language spoken by more than one million people in Zambia and Zimbabwe (Simons \& Fennig, 2017). Crosslinguistic studies of SI have been completed (e.g., Papafragou \& Musolino, 2003; Röhrig, 2010); however, Bantu languages have not been included in these studies.

The goal of the current study is to determine if Chitonga-speaking children who are over the age of six, the critical age for studies of SI acquisition, interpret sentences with SI in an adult-like manner, following Grice's Maxims. This study employs a methodology similar to that of Papafragou and Musolino (2003), and tests the interpretation of some, all, and cardinal numbers. Importantly, as was done by Papafragou and Musolino, this study uses a training phase so that participants respond not in terms of truth conditions, but in terms of pragmatics, indicating whether or not a sentence is well-formed and adhering to conversational maxims. Based on the results of previous studies, we hypothesize that the order of acquisition for SI in Chitonga is similar to what has been identified by previous studies and that the children, since they are beyond the age of six, will have adult-like interpretations for all items in the study. However, if any variability is observed, we expect that less adult-like interpretations are produced by younger

\footnotetext{
${ }^{1}$ See Foppolo et al. (2012) for a summary of SI and previous research on adult-like interpretations as well as research with children.
} 
children and more adult-like interpretations are produced by older children. We also expect, in the case of variability, the most adult-like performance to occur with cardinal numbers and the least adult-like performance to occur with some.

2.1. PARTICIPANTS. Twenty-five Chitonga-speaking children living in rural Southern Province, Zambia participated in this study. They were ages 7-15 (mean = 11.5), notably over the age of six, the age after which it has been demonstrated that children have adult-like interpretations of SI. Data from seven additional children were not included in the analysis for the following reasons: (1) participants were outside of the age range as defined, (2) participants had missing age information, and (3) participants answered with a single consistent response to all items.

2.2. MATERIALS. The study included a series of picture pairs that depict children and adults before and after actions are completed. The picture pairs were partnered with sentences, one for each picture. The first sentences (henceforth scenario sentences) did not include any SI items. They were simple sentences to accurately describe the pictures. The subsequent sentences (henceforth test sentences) included SI words and did not always match the expected adult interpretation of the pictures. There were sixteen pairs: eight with cardinal numbers in the test sentences, four with some in the test sentences, and four with all in the test sentences. Four additional items were included in testing, but were not included in the analysis because the data revealed that either the sentences or the pictures were unclear to the participants. Below are two examples of the picture and sentence pairs.

(4) Scenario

$\begin{array}{llll}\text { Mulimi uyanda kujika } & \text { nkuku } & \text { kuli } & \text { bambila cilyo caku.mazuba. } \\ \text { farmer wants cook } & \text { chicken } & \text { in } & \text { prepare food for.day }\end{array}$

"The farmer wants to cook chickens for a special dinner."

(5) Test

Mulimi wajika nkuku zimwi buyo.

farmer cooked chicken other just

"The farmer cooked some of the chickens."
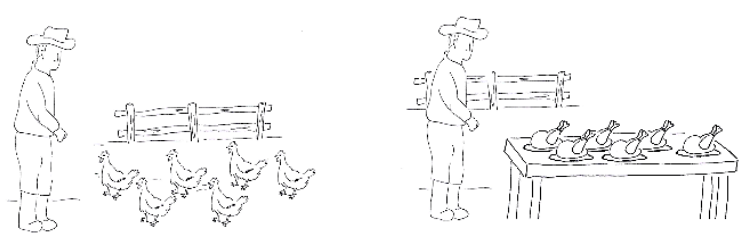

Figure 1. Some example 
(6) Scenario

Mulimi uyanda kusambala mpongo.

farmer wants sell goat

"The farmer wants to sell goat(s)."

(7) Test

Mulimi wakasambala mpongo zyobile ku mwalumi.
farmer sold goat two to man
"The farmer sold two goats to the man."

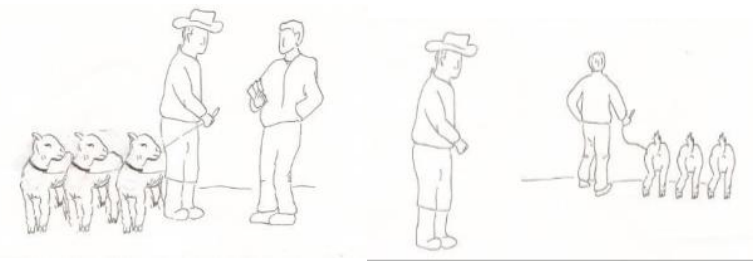

Figure 2. Cardinal number example

All materials were generated collaboratively by linguists and native speakers of Chitonga. All items were initially generated in English, but were translated and back-translated to confirm that they conveyed the intended meaning in natural and grammatical Chitonga. Sentences were also reviewed by project members who grew up in the same village area in which the data were collected in order to confirm that the content and vocabulary of the sentences were appropriate for the cultural and educational context.

2.3. PROCEDURE. For each item, the child listened to a puppet say the scenario sentence and viewed the scenario picture. The child was then shown the test picture and heard the puppet say the test sentence. After each test sentence, the child was asked if the puppet described the picture well. Following Papafragou and Musolino (2003), the child was not asked if the puppet said a correct sentence, but instead if the puppet described the picture well. This was done in an effort to guide the child towards responses about felicity and not truth judgments. If the child indicated that the puppet did not describe the picture well, they were asked to state why. This step was completed whether or not the child's response was adult-like.

A training session was employed, also following the methods of Papafragou and Musolino (2003), in order to make sure that the child understood that the task at hand requires judgment of pragmatic felicity and not grammaticality. The first of the three training items was simply to have the students respond to the puppet. The remaining items were grammatically correct, but 
did not always match the picture well (e.g., describing a picture of a dog as a four-legged animal instead of using the word $d o g$ ).

3. Results. Mean performance by SI type are provided in Table 1 below.

\begin{tabular}{|l|l|}
\hline Item Type & $\begin{array}{l}\text { Mean Adult-like } \\
\text { Responses }\end{array}$ \\
\hline Cardinal Numbers & $76 \%$ \\
\hline Some & $57 \%$ \\
\hline All & $69 \%$ \\
\hline
\end{tabular}

Table 1. Mean Performance

Correlations were checked between performance on each item type and participant characteristics, but no correlations were found $(p<.05)$. Further, no correlations were observed on performance between sets of items by type $(p<.05)$.

Performance was analyzed using a repeated measures ANOVA. Performance was significantly higher for cardinal numbers than for sentences with some $(p<.03)$. No significant difference was observed between cardinal numbers and all or between all and some.

4. Discussion. We hypothesized that the children, who were over the age of six at the time of collection, would have adult-like SI interpretations. We expected that the use of a training session and then the format of the question would guide participants towards evaluating pragmatic felicity over providing truth value judgments, and would result in adult-like interpretations. Further, we posited that if our initial hypothesis was not supported, and in fact there was some non-adult-like performance, that there would be significant variability among the conditions, with cardinal numbers having the highest performance and some the weakest. On the surface, it does seem as if there is variability and perhaps a larger sample size or more items could lead to a significant finding (see limitations below), but at least for this study, the only significant finding was the difference between cardinal numbers and some. Significant differences were not observed between all and cardinal numbers or all and some.

4.1. LIMITATIONS AND FUTURE DIRECTIONS. This study is limited in its power and generalizability. It serves as a reminder of the work that needs to be completed for the crosslinguistic study of SI in particular and acquisition more generally. Bantu languages are not included in studies of acquisition often enough despite the numerous languages in this linguistic grouping and the millions of people using them. Future studies need to include more participants and more items to increase power. Future studies should also include a larger age range of children to document the age at which adult-like performance emerges. Related cross-cultural 
studies have resulted in insufficient statistical power, but interesting trends (e.g., Nedwick, 2014). Follow-up studies with increased stimuli and participants are needed.

In a future study, it is also important to consider if additional training in the difference between reporting on felicity and truth value judgments would impact results, or if more naturalistic experimental conditions (e.g., demonstrating actions using real objects instead of twodimensional depictions) would be beneficial. Previous studies in this region of sub-Saharan Africa have found evidence of cultural differences in testing behavior (Hein, Reich, Marks, Thuma, \& Grigorenko, 2016). The current study is too small to make strong conclusions with regard to cultural differences and experimental methods; however, in the study by Hein and colleagues it was found that children responded more or less frequently based on factors such as stimuli type. In the current study, the responses from two children were not included because they responded the same way to every item through the training and all test items. More specifically, they answered "yes" that the puppet described the pictures well. It is possible that these two children understood the task and really did believe that the puppet did not produce any poor descriptions, and in this regard, are not yet adult-like in their SI interpretations. This is unlikely as they said that even the first training item was said well. It is also possible though that these two children were attempting to please the data collectors, or be polite, and that "yes" was in some ways a default answer to be provided when having to respond verbally in a test context.

Additional training with the methodology could improve outcomes. The puppets used were picked specifically for this task with careful attention to their appearance. Upon arrival at the school, however, it became clear that the children were not accustomed to playing with puppets and that the data collection would be a novel experience for them. Further exploration with greater cardinal number ranges could also prove interesting. Numbers through five in the participating communities are most often expressed with native Chitonga words while numbers greater than five are typically indicated using English borrowings. The cardinal numbers included in this study were only one through five in order to avoid additional item variability, but larger numbers should be included in future research.

5. Conclusion. Albeit limited, these results provide valuable insight into SI interpretation by Chitonga-speaking children and demonstrate that pragmatic inference acquisition likely follows the order identified in previous research, but appears to be completed at a later age in this language. This interesting combination of findings - expected hierarchy of difficulty, but differing age of acquisition - is an important addition to our growing cross-linguistic knowledge of SI and could be the result of language-specific differences in the use of SI lexical items or methodological differences.

\section{References}

Barner, D., \& Bachrach, A. (2010). Inference and exact numerical representation in early language development. Cognitive Psychology, 60(1), 40-62. 
Chierchia, G., Crain, S., Guasti, M.T., Gualmini, A., \& Meroni, L. (2001). The acquisition of disjunction: Evidence for a grammatical view of scalar implicatures. BUCLD 25, 157168. Somerville, MA: Cascadilla Press.

Foppolo, F., Guasti, M.T., \& Chierchia, G. (2012). Scalar implicatures in child language: Give children a chance. Language Learning and Development, 8(4), 365-394.

Gopnik, A., \& Rosati, A. (2001). Duck or rabbit? Reversing ambiguous figures and understanding ambiguous reference. Developmental Science, 4(2), 174-182.

Grice, H. P. (1957). Meaning. The Philosophical Review, 66, 377-388.

Hein, S., Reich, J., Marks, S., Thuma, P. E., \& Grigorenko, E. L. (2016). Getting something out of nothing: Analyzing patterns of null responses to improve data collection methods in sub-Saharan Africa. Learning and Individual Differences, 46, 11-16.

Horn, L. (1972). On the Semantic Properties of Logical Operators in English. Ph.D. thesis, UCLA, Los Angeles, CA.

Huang, Y.T., \& Snedeker, J. (2009). Semantic meaning and pragmatic interpretation in 5-year olds: Evidence from real-time spoken language comprehension. Developmental Psychology, 45(6), 1723-1739.

Kennedy, Christopher. "A scalar semantics for scalar readings of number words." From grammar to meaning: The spontaneous logicality of language (2013): 172-200.

Nedwick, K. (2014). Metalinguistic Negation in English and Arabic (Unpublished doctoral dissertation). Yale University, New Haven, CT.

Noveck, I. A. (2001). When children are more logical than adults: Experimental investigations of scalar implicature. Cognition, 78(2), 165-188.

Papafragou, A., \& Musolino, J. (2003). Scalar implicatures: Experiments at the semantics pragmatics interface. Cognition, 86(3), 253-282.

Röhrig, Stefanie. (2010). The Acqusition of Scalar Implicatures, 3. Universitätsverlag Göttingen.

Shallice, T. (1982). Specific impairments of planning. Philosophical Transcripts of the Royal Society of London B, 298, 199-209.

Simons, G. F., \& Fennig C. D. (Eds.). (2017). Ethnologue: Languages of the World, Twentieth edition. Dallas, TX: SIL International. Online version: http://ethnologue.com. 